Águas Subterrâneas (2017) 31(1):104-116.

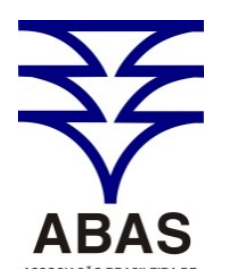

ASSOCIACAO BRASILERADE
AGUAS SUBTERRANEAS www.abas.org

\section{ESTIMATIVA DE RECARGAS HÍDRICAS SUBTERRÂNEAS POTENCIAIS VOLUNTÁRIAS E INVOLUNTÁRIAS EM ÁREAS URBANAS}

\author{
ESTIMATE OF VOLUNTARY AND INVOLUNTARY POTENTIAL \\ GROUNDWATER RECHARGES IN URBAN AREAS
}

Filipe da Silva Peixoto ${ }^{1}$; Itabaraci Nazareno Cavalcante ${ }^{1}$; Renata Nayara Câmara Miranda Silveira' ${ }^{1}$ Karen Vendramine de Araújo ${ }^{1}$

Artigo recebido em: 11/04/2016 e aceito para publicação em: 28/12/2016.

DOI: http://dx.doi.org/10.14295/ras.v31i1.28621

Resumo: O estudo buscou quantificar a recarga potencial de água subterrânea em bairros localizados em subbacias urbanas na cidade de Fortaleza - Ceará considerando, para isto, as recargas potenciais naturais de origem pluvial e a recarga potencial artificial, esta proveniente dos vazamentos na rede de abastecimento e dos Sistemas Estáticos de Esgotamento Sanitário - SEES representados, respectivamente, pela Recarga Hídrica Natural Potencial - RHNP e Recarga Hídrica Artificial Involuntária Potencial - RHAIP. Produziu-se um modelo de fluxo hídrico subterrâneo visando à identificação de áreas de recarga e descarga. Foi aplicado o método do balanço hídrico para a quantificação da RHNP. A estimativa do RHAIP foi realizada com auxílio de dados do Censo de 2010 do Instituto Brasileiro de Geografia e Estatística - IBGE, que foram dispostos e analisados em Sistema de Informação Geográfica - SIG. Os volumes de RHNP são superiores aos de RHAIP que, por sua vez, representam 1,07 milhões de $\mathrm{m}^{3}$ /ano de efluentes domésticos via SEES e por vazamentos na rede geral de distribuição de água, que possui volume estimado em 1,51 milhões de $\mathrm{m}^{3} /$ ano considerando-se um consumo diário per capita de $225 \mathrm{~L} / \mathrm{hab}$. A recarga total foi estimada em 12,3 milhões de $\mathrm{m}^{3}$ /ano, sendo que a RHAIP é responsável por 20,9\% da recarga potencial total.

Palavras chave: Recarga involuntária. Área Urbana. Água subterrânea.

Abstract: The objective of the study is to quantify the potential groundwater recharge in urban sub-basins in the city of Fortaleza - Ceará. We considered for this natural potential recharge of rain origin and artificial potential recharge that comes from leaks in the supply network and Sanitary Static Sewage System - SSSS, represented respectively by Hydric Potential Natural Recharge - HPNR and Hydric Potencial Artificial Involuntary Recharge - HPAIR. We produces groundwater flow model to identify recharge and discharge areas. The water balance method was applied for the quantification of the HPNR. The estimated HPAIR we accomplished a Geographic Information System - GIS analyze with 2010 Census data to aid the IBGE to observe the sanitation situation of the area. The HPNR' volume ware superior to HPAIR, that, are constituted by 1,07 million $\mathrm{m}^{3} /$ year of domestic effluents via SSSS, and leaks in the water supply network. These has volume estimated at 1.51 million $\mathrm{m}^{3}$ year considering a daily per capita consumption of $225 \mathrm{~L} / \mathrm{hab}$. The total potential recharge was estimated at 12.3 million $\mathrm{m}^{3} /$ year, and the HPAIP is responsible for $20.9 \%$ of the total potential charge.

Keywords : Involuntary recharge. Urban area. Groundwater.

\section{INTRODUÇÃO}

Em um mundo de urbanização crescente, estima-se que dois terços da população mundial será urbana em 2050 (UN, 2005). Existe uma grande necessidade do gerenciamento das águas urbanas, particularmente das águas subterrâneas que podem atuar como mananciais na própria área física da cidade. Segundo Foster et al. (1999) e Foster e Chilton (2004), o uso destas águas em ambiente urbano precisa ser racionalizado considerando-se a qualidade exigida pelos usos e os potenciais serviços

\footnotetext{
${ }^{1}$ Universidade Federal do Ceará (UFC). E-mails: (fpeixoto10ufc@gmail.com, itabaracicavalcante@gmail.com, rnayarac@gmail.com.br, karenvendramini@yahoo.com.br)
} 
ambientais prestados pelo meio hidrogeológico, possibilitando a estratégias de uso privado da água, disposição de efluentes e reuso da água.

Dessa forma, é possível viabilizar um gerenciamento integrado das águas urbanas, sendo essencial a quantificação dos volumes de recarga hídrica, principalmente das Recargas Hídricas Artificiais Involuntárias Potencial - RHAIP, que podem exercer influências quali-quantitativas nas águas subterrâneas das cidades carecendo, assim, de quantificação para viabilizar o gerenciamento do recurso hídrico urbano.

Os mecanismos de recargas de água subterrânea no meio urbano são complexos, por conta da diversidade de fontes potenciais. Considerando os aquíferos livres, a fonte de recarga majoritária é de origem pluviométrica mas, no entanto, há contribuição das águas servidas e efluentes de esgotos (BARRET et al., 1999). Segundo Lerner (1999, 2002), os vazamentos da rede de distribuição de água e coleta de esgoto, as águas provenientes de irrigação e Sistemas Estáticos de Esgotamento Sanitário - SEES’s são fontes de recargas não naturais. Este último é caracterizado como a forma de disposição de dejetos via fossa séptica, rudimentar ou vala de infiltração, cujos efluentes são incorporados localmente ao subsolo, e parte são incorporados às águas subterrâneas.

De fato, as águas oriundas da rede de distribuição da CAGECE e que por vazamentos são incorporadas ao sistema hídrico subterrâneo, possuem origem externa a área de Fortaleza, sendo captadas de vários açudes, a exemplo do Sistema PacotiRiachão-Gavião ou do açude Castanhão.

$\mathrm{O}$ volume das contribuições da RHAIP varia em função dos sistemas de esgotamento sanitário e da eficiência da rede de abastecimento. Como exemplo, observa-se que na cidade de Tomski - Rússia, a taxa de contribuição da RHAIP chega a 30\% da recarga total (POKROVISK, 1999). Segundo Lerner $(1990,2002)$, é comum que estas cheguem a $25 \%$, e até $50 \%$ em casos mais extremos, como em grandes cidades de climas áridos ou semiáridos.

Para se estimar a recarga hídrica em áreas urbanas, é frequentemente utilizado o monitoramento dos níveis d’água em conjunto com o balanço hídrico, ou mesmo por meio da assinatura química das águas. Lerner (1990) e Chae et al. (2010) utilizaram o monitoramento do nível estático de poços, associados ao balanço hídrico, para estimarem a RHAIP nas cidades de Hong Kong e Seul, respectivamente. Choi et al. (2012) aplicaram este mesmo método em uma análise da evolução temporal para quantificação da RHAIP entre os anos de 1970 e 2000 na cidade de Waukhesha - EUA. Barret et al. (1999) e Vasquez-Suñe et al. (2010) identificaram três fontes principais de RHAIP's nas cidades de Notthingham e Barcelona, sendo eles os efluentes indústrias, domésticos e vazamentos da rede de abastecimento e, para isso, foi utilizada a assinatura química em análises físicoquímicas, bacteriológicas e isotópicas. Lerner et al., (2002) utilizaram o balanço hídrico para aferir a recarga de originada de efluentes, ao comparar a quantidade destes em fluxos de rede coletora e SEES.

. O estudo foi realizado em bairros periféricos da cidade de Fortaleza - CE, onde as águas subterrâneas exercem um importante papel para o abastecimento urbano. Essas águas são "utilizadas prioritária ou estrategicamente por 40 a $60 \%$ da população na Região Metropolitana de Fortaleza” (CAVALCANTE, 1998). Neste caso, em Fortaleza o uso predominante corresponde ao abastecimento doméstico, que compreende $75 \%$ das captações, ressaltando-se que existem cerca de 8.000 poços cadastrados desde 2002 (GOMES, 2013). O estudo buscou quantificar a recarga potencial de água subterrânea considerando, para isto, as recargas potenciais naturais de origem pluvial e a recarga potencial artificial, esta proveniente dos vazamentos na rede de abastecimento e dos SEES's representados, respectivamente, pela RHNP e RHAIP. 


\section{2 ÁREA DE ESTUDO}

A área investigada corresponde a oito (8) bairros de Fortaleza, parcial ou integralmente, inseridos em quatro subbacias hidrográficas urbanas no Município de Fortaleza - CE, sendo estas conseguintes e inseridas na Bacia Hidrográfica do rio Cocó,
Região Metropolitana de Fortaleza - RMF. Esta área insere-se na Secretaria Regional VI (SER VI), abrangendo total, ou parcialmente, os bairros de Messejana, Curió, Guajerú, José de Alencar, Cambeba, Sapiranga, Lagoa Redonda e Cidade dos Funcionários (Figura 1).

Figura 1 - Mapa de localização da área de estudo

Figure 1 - Study area

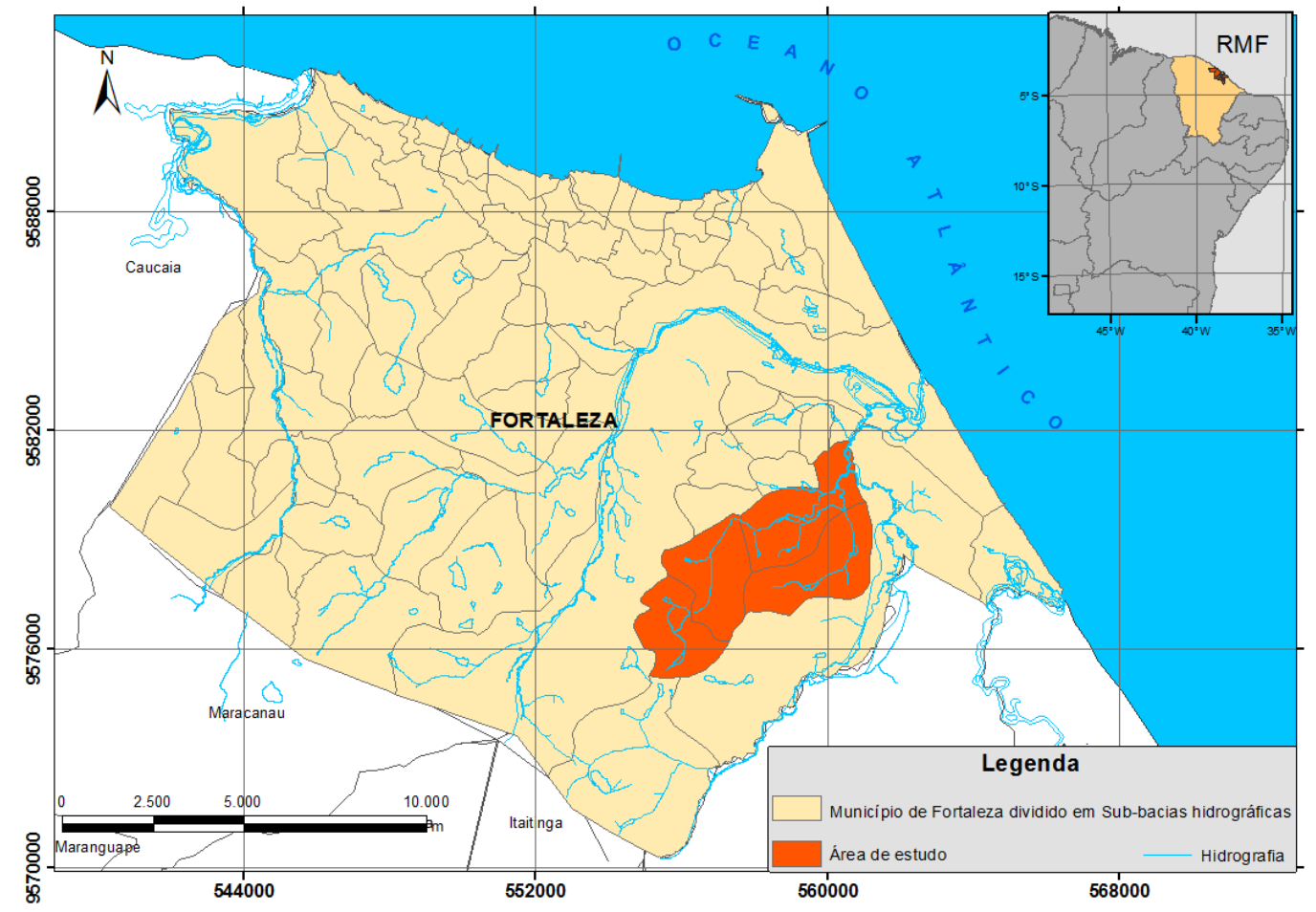

Observa-se a presença de aquíferos livres que favorece a influência da RHAIP, haja vista que a recarga das águas de superfície e sub-superfície ocorre por gravidade. São dois os domínios hidrogeológicos, com distintas vocações aquíferas: o Sedimentar, representado pela Formação Barreiras, com espessura média de 27 metros, sobreposto diretamente sobre o embasamento cristalino; e o Cristalino, representado pelo embasamento geológico constituído pelo Complexo Gnáissicomigmatítico, onde se observa inicialmente o manto de alteração com espessura média de quatro (4) metros.

O Sistema Hidrogeológico Barreiras é formado por litotipos clásticos silto-arenoargilosos, com espessuras oscilando de 20 a 60 metros (CAVALCANTE, 1998; GOMES,
2013). No Município de Fortaleza as suas características hidrodinâmicas são muito variáveis, com nível estático predominantemente inferior a 10 metros e vazões que podem atingir $15 \mathrm{~m}^{3} / \mathrm{h}$, predominantemente nos bairros do Pici, porção sul do Conjunto Palmeiras, Pirambú e Álvaro Weyne (GOMES e CAVALCANTE, 2015) mas, contudo, estas vazões são predominantemente inferiores a $2,0 \mathrm{~m}^{3} / \mathrm{h}$ (40\%), com média de 2,8 $\mathrm{m}^{3} / \mathrm{h}$ (CAVALCANTE, 1998).

O Cristalino, muitas vezes entendido como Aquífero Fraturado, possui baixa porosidade primária que resulta em valores normalmente inferiores a 1\% (FEITOSA et al., 2008). Segundo Cavalcante (1998, p. 43) "As rochas do embasamento Pré-cambriano representam um contexto de pequena 
vocação para armazenamento e captação de água subterrânea, decorrente da ausência quase que total de porosidade e condutividade hidráulica primária”. Nesse tipo de rocha, a ocorrência de reservas hídricas subterrâneas consideráveis fica sujeita à fraturas abertas, que produzem uma porosidade secundária, ou do manto de alteração da rocha matriz, capazes de reter e transferir água. No município de Fortaleza, os poços que captam água dessa unidade possuem profundidade média de 60 metros, nível estático inferior a 15 metros, vazão média de $2 \mathrm{~m}^{3} / \mathrm{h}$ e capacidade específica inferior a $1\left[\left(\mathrm{~m}^{3} / \mathrm{h}\right) / \mathrm{m}\right]$ (CAVALCANTE, 1998; GOMES, 2013).

\section{METODOLOGIA}

A metodologia utilizada nesta pesquisa é representada por etapas que envolvem desde a pesquisa de dados secundários (Précampo) até a coleta de dados primários em campo, descritas a seguir.

\subsection{Etapa Pré-campo}

Esta etapa consistiu no levantamento de poços cadastrados na Secretaria de Recursos Hídricos do Ceará - SRH (CEARÁ, 2002); no Sistema de Informações de Águas Subterrâneas - SIAGAS (2015); nas bases temáticas integradas na base geológica obtida do Serviço Geológico Brasileiro - CPRM (2004) e no ATLAS dos Recursos Hídricos Subterrâneos do Ceará (2002). Os dados de população e situação de esgotamento sanitário foram obtidos do Censo de 2010 do Instituto Brasileiro de Geografia e Estatística - IBGE e os dados climatológicos foram cedidos pela Estação Meteorológica da Universidade Federal do Ceará - UFC, localizada no Campus Universitário do Pici Fortaleza.

Para a seleção dos poços a serem visitados foram considerados os seguintes critérios: $1^{\circ}$ - Existência de perfil litológico e técnico-construtivo; $2^{\circ}$ - Poços em funcionamento; $3^{\circ}$ - Distribuição espacial favorável à representatividade da área de estudo.

\subsection{Etapa de campo}

A etapa de campo consistiu na visita a 25 poços tubulares (18) e manuais (07). Estes últimos são representados por cacimbas que possuem revestimentos de pré-moldados, ou alvenaria, com maior diâmetro (máximo de 2 metros) e menor profundidade (máxima de 15 metros) que os poços tubulares. Esta etapa ocorreu entre 18 de junho e 10 de julho de 2015, na qual foram medidas as coordenadas UTM em datum WGS-84, por meio de receptor GPS, além da medição de níveis estáticos de 25 poços utilizando um medidor de nível d’água eletro-sonoro Solinst.

\subsection{Etapa pós-campo}

\subsubsection{Fluxo hídrico subterrâneo}

O mapa de fluxo hídrico foi elaborado com base no cálculo da carga hidráulica, calculada a partir de medidas do nível estático e das cotas da boca do poço. A carga hidráulica, ou potencial hidráulico, é a energia mecânica de um liquido em movimento e, de acordo com Fetter (1993), pode ser expressa pela Equação 1.

$$
\mathrm{h}=\mathrm{z}+\mathrm{p} / \gamma
$$

onde: h - Carga hidráulica; z - elevação do nível (m); p - massa específica sobre o volume; $\gamma$ - peso específico sobre o volume.

Como em aquíferos livres "p" é nulo, pois a pressão será sempre correspondente à atmosférica, tem-se que $\mathrm{h}=\mathrm{z}$. Assim (Equação 2):

$$
\mathrm{h}=\mathrm{C}-\mathrm{NE}
$$

onde: h - Carga Hidráulica; NE - nível estático (m); c - cota altimétrica (m).

A cota altimétrica foi obtida da carta topográfica do município de fortaleza, escala 1: 2000, com resolução altimétrica de 2 
metros (Fortaleza, 1972) e o nível estático foi medido em campo (Tabela 1).

Tabela 1 - Valores para cálculo de carga hidráulica na área de pesquisa

Table 1 - Values for hydraulic force calculation

\begin{tabular}{|c|c|c|c|c|c|}
\hline \multicolumn{2}{|c|}{ Coordenadas } & \multirow[b]{2}{*}{ NE (m) } & \multirow[b]{2}{*}{$\mathbf{A b}$} & \multirow[b]{2}{*}{ C } & \multirow[b]{2}{*}{ CH } \\
\hline N (UTM) & E (UTM) & & & & \\
\hline 9575860 & 555340 & 10.14 & 0.70 & 29.2 & 19.76 \\
\hline 9578126 & 555632 & 4.87 & 0.50 & 23.7 & 19.33 \\
\hline 9576546 & 556015 & 3.12 & 0.50 & 20.0 & 17.38 \\
\hline 9577270 & 556104 & 3.70 & 0.30 & 23.5 & 20.10 \\
\hline 9579554 & 556548 & 5.31 & 0.07 & 21.1 & 15.86 \\
\hline 9579736 & 556619 & 1.90 & 0.27 & 14.9 & 13.27 \\
\hline 9579746 & 556648 & 1.91 & 0,00 & 10.0 & 8.09 \\
\hline 9576298 & 556732 & 5.67 & 0.10 & 26.1 & 20.53 \\
\hline 9578636 & 557277 & 11.13 & 0.10 & 19.5 & 8.47 \\
\hline 9575960 & 557411 & 1.60 & 0.80 & 24.7 & 23.90 \\
\hline 9579114 & 558309 & 7.03 & 0.08 & 7.2 & 0.25 \\
\hline 9579284 & 558355 & 3.28 & 0.95 & 6.7 & 4.37 \\
\hline 9578202 & 558798 & 7.50 & 0.60 & 20.0 & 13.10 \\
\hline 9578158 & 558799 & 8.50 & 0.80 & 20.0 & 12.30 \\
\hline 9579742 & 558889 & 1.40 & 0.42 & 11.6 & 10.62 \\
\hline 9576884 & 559190 & 10.22 & 0.30 & 20.0 & 10.08 \\
\hline 9580274 & 559228 & 4.20 & 0.63 & 5.5 & 1.93 \\
\hline 9579230 & 560132 & 3.63 & 0.40 & 10.0 & 6.77 \\
\hline 9579128 & 560212 & 2.50 & 0.14 & 10.0 & 7.64 \\
\hline 9579128 & 560212 & 10,00 & 0.28 & 14.0 & 4.28 \\
\hline 9579458 & 560322 & 3.48 & 0.50 & 5.1 & 2.12 \\
\hline 9579438 & 560333 & 3.30 & 0.30 & 5.0 & 2.00 \\
\hline 9577728 & 560777 & 4.50 & 0.90 & 15.0 & 11.40 \\
\hline 9579106 & 560885 & 7.10 & 0.73 & 11.5 & 5.13 \\
\hline 9579136 & 561113 & 8.67 & 0.40 & 15.0 & 6.73 \\
\hline
\end{tabular}

LEGENDA: NE - Nível estático; Ab - altura da boca do poço; C - cota altimétrica; CH - Carga Hidráulica

Em aquíferos livres formados por sedimentos ou rochas sedimentares que apresentam comportamento típico de meios porosos clásticos, o mapa de fluxo pode identificar áreas de recarga, principalmente em função do comportamento aquífero e com recarga diretamente associada a contribuição pluviométrica.

A identificação do tipo de fluxo hídrico subterrâneo contribui para a caracterização do tipo de aquífero. Tal etapa é importante, haja vista, que a metodologia aqui empregada deve ser aplicada apenas em aquíferos livres.

\subsubsection{Recarga Hídrica Natural Potencial}

O volume de recarga constitui a quantidade de água que é efetivamente incorporada à zona saturada. Isso ocorre a partir do mecanismo de infiltração da água, em que esta percola o meio subterrâneo preenchendo os espaços vazios, correspondentes aos poros, ou fraturas, até anular a capacidade de campo deste, quando ocorre então o deslocamento hídrico por gravidade e adição hídrica ao volume armazenado (MANOEL FILHO, 2000). Para Lerner et al. (1990), a recarga hídrica subterrânea é definida como o fluxo descendente que recarrega o "lençol" freático, causando adição hídrica ao reservatório.

Estimativas de volume de recarga podem ser também realizadas por meio do tratamento de dados da vazão de rios, através dos hidrogramas correspondentes ao fluxo de base do rio. Pode ser realizado, ainda, a partir do método do deslocamento da curva de recessão, o que consiste de uma série de cálculos visando estimar a recarga total para 
cada pico da vazão (RUTLEDGE e DANIEL, 1994).

No entanto, como a área de estudo é drenada por pequenos canais, restritos e intermitentes, e visto a falta de dados de monitoramento, foi adotado o método do balanço hídrico climático que se mostrou mais apropriado para a quantificação da RHNP. Lerner et al. (1990) colocam que existe uma clara distinção conceitual com relação a modelos propostos, entre os que mensuram a quantidade de água disponível para recarga através das zonas superficiais do solo, e os que quantificam o volume de água efetivamente adicionado. Aqui se emprega o conceito entre a recarga potencial e a recarga efetiva quantificada pelos modelos, entendendo-se que parte do volume de recarga irá perder-se em função das características do corpo aquífero, da distribuição dos solos e dos usos associados a este (MUNÉVAR e MARIÑO, 1999).

O balanço hídrico climático anual é um importante indicador que reflete a disponibilidade hídrica natural quanto às características climáticas. Ele consiste basicamente na diferença entre precipitação média (P) e evapotranspiração média (ETP) de cada mês do ano. De acordo com Sokolov e Chapman (1981, p. 12), "A partir de um estudo de balanço hídrico é possível a avaliação quantitativa de recursos hídricos e suas modificações por influência das atividades antrópicas”.

Foi utilizado o método do balanço hídrico climático com base em Castany (1975), que parte da equação geral do balanço hídrico e propõe a aplicação da Equação 3:

$$
\mathrm{I}_{\mathrm{e}}=\mathrm{PPT}-\mathrm{ETR}
$$

Onde: $\mathrm{I}_{\mathrm{e}}=$ Infiltração Efetiva (mm); PPT = Precipitação (mm); ETR = Evapotranspiração Real (mm).

Castany (1975) considera que o escoamento superficial é insignificante, por conta de características morfológicas do solo que propiciam boa permeabilidade e infiltração.
Os dados climatológicos utilizados foram cedidos pela Estação Meteorológica localizada no Campus do Pici/UFC, dispostos em tabela (Tabela 1) e gráfico (Figura 3), facilitando o entendimento hidroclimático da área de estudo e a estimativa de recarga anual. Foi utilizada uma série histórica de 48 anos, que engloba o período entre 1966 a 2014.

A ETP foi calculada segundo a expressão de Thorntwaith (1948), enquanto o volume de recarga anual foi calculado com base na Equação 4:

$$
\mathrm{R}=\mathrm{I}_{\mathrm{e}} . \mathrm{A}
$$

Onde: R - Recarga anual $\left(\mathrm{mm}^{3}\right)$; $\mathrm{I}_{\mathrm{e}}$ Infiltração efetiva (mm); A - Área considerada $\left(\mathrm{m}^{2}\right)$.

\subsubsection{Recarga Hídrica Artificial Involuntária Potencial}

A RHAIP foi calculada conforme a sua origem e, desse modo, foram caracterizadas separadamente a contribuição dos efluentes domésticos e dos vazamentos na rede de abastecimento.

A recarga potencial por efluentes domésticos foi mensurada com base nos dados da situação sanitária e do abastecimento na área de estudo. Para isso partiu-da quantificação de efluentes segundo Von Sperling (2009) (Equação 5).

$$
\mathrm{Q}_{\mathrm{d}(\mathrm{m})}=\frac{\text { Pop.QPC. }}{1000}
$$

Onde: $\mathrm{Q}_{\mathrm{d}(\mathrm{m})}$ - Vazão média de esgoto doméstico ( $\left.\mathrm{m}^{3} / \mathrm{dia}\right)$; Pop - População $\left(\mathrm{n}^{0}\right.$ de habitantes); QPC - Quota per capita de consumo (hab/dia); R - Coeficiente de retorno esgoto/água.

Considerando as condições sanitárias da área de estudo, propôs-se o cálculo da recarga artificial de efluentes domésticos de acordo com a Equação 6.

$$
\mathrm{Ra}_{(\mathrm{m})}=\frac{(\text { Pop. Pops) } \mathrm{x} \text { QPC }}{1000}
$$


Onde: $\mathrm{Ra}(\mathrm{m})$ - recarga média artificial ( $\left.\mathrm{m}^{3} / \mathrm{dia}\right)$; Pops - proporção de população sem serviço de esgotamento sanitário via rede geral ou pluvial (\%).

$O$ coeficiente de retorno " $R$ " foi desconsiderado, já que este significa a fração de água fornecida que adentra a rede de coleta na forma de esgoto, de forma que a referida equação considera para esse cálculo somente os SEES's.

Para a quota per capita de consumo adotou-se o valor de 225 (L/hab/dia) ao se considerar que para cidades com população superior a 250.000 habitantes, esse consumo varia de 150 a 300 [L/hab)/dia] (CETESB,1978). Foi considerado, portanto, a média entre esses valores.

A recarga proveniente de vazamentos na rede geral de abastecimento foi calculada a partir da demanda com relação a índices de perdas estimado em $22,5 \%$ de acordo com relatório da Companhia de Água e Esgoto do Ceará - CAGECE em 2008 (MORAIS, 2011) (Equação 7).

$$
\operatorname{RHAIP}(\mathrm{ab})=\left(\mathrm{Pop}_{\mathrm{ab}} \cdot \mathrm{Q}_{\mathrm{pc}}\right) \cdot \mathrm{Ip}
$$

Onde: RHAIP(ab) - Recarga Hídrica Artificial Involuntária Potencial proveniente de vazamentos na rede de abastecimento $\left(\mathrm{L}^{3} \mathrm{~T}^{-1}\right) ; \quad$ Pop $(\mathrm{ab}) \quad$ - População com abastecimento de água via rede geral $\left(\mathrm{n}^{\mathrm{o}}\right.$ de habitantes; $\mathrm{Q}_{\mathrm{pc}}$ - consumo per capita ( $\left.\mathrm{m}^{3} / \mathrm{dia}\right)$; Ip - Índice de perdas (\%).

A quantidade e proporção da população sem serviço de esgotamento sanitário via rede geral, ou pluvial, e com abastecimento de água via rede geral foram identificadas conforme os dados do Censo 2010 do IBGE, organizados em SIG e calculados por setores censitários.

\section{RESULTADOS E DISCUSSÕES}

O entendimento do fluxo da água subterrânea é de grande importância na identificação de áreas de recarga e descarga dos aquíferos, assim como dos tipos de recarga associados. As áreas de recarga são caracterizadas pela dispersão do fluxo, representando áreas de maiores valores de carga hidráulica tendo em vista que a água se desloca da maior para a menor pressão. Além disso, o mapa de fluxo pode detectar possíveis heterogeneidades no meio geológico (DEMÉTRIO et al., 2014).

É observada a disposição geral do fluxo hídrico na direção dos níveis de base representados pelos corpos hídricos superficiais. Tal propriedade corresponde a parâmetros hidrodinâmicos típicos de meio porosos, com permeabilidade favorável ao fluxo hídrico no sentido do relevo. Desse modo, as lagoas e rios possuem um comportamento efluente ao Sistema Hidrogeológico Barreiras sendo, portanto, alimentado pelo fluxo de base na maior parte do ano (Figura 2). O Barreiras comporta-se como aquífero livre, onde a recarga pluvial é a principal fonte natural de recarga.

O mapa de fluxo contribuiu para a caracterização do aquífero livre, com recarga eminentemente pluviométrica. Tal característica condiciona uma maior vulnerabilidade aos efeitos do uso e ocupação do solo, pois o nível estático se encontra demasiado próximo ao nível do solo, freático, com média de 6,6 metros.

\subsection{Estimativas de recarga}

O cálculo de balanço hídrico é utilizado para se estimar a recarga de aquífero. Vasconcelos (1999, p. 174) coloca que “A quantificação da recarga de águas subterrâneas através do balanço hídrico é um processo estimativo, uma vez que utiliza valores médios de séries históricas na equação de balanço de massa”. Sokolov e Chapman (1981) consideram que o conhecimento do balanço hídrico de uma região possibilita uma avaliação indireta de qualquer componente dentro desta. Assim, a partir dos dados de balanço hídrico climático estimou-se a infiltração média efetiva que por sua vez corresponde a RHNP.

A lâmina de água em milímetros (mm) disponível para a infiltração resulta da diferença entre "P" (Precipitação) - "ETP" (Evapotranspiração Potencial). Quando a "P” 
não ultrapassa o valor em $\mathrm{mm}$ da "ETP", considera-se "ETR = P". Quando a "P" ultrapassa o valor da "ETP" ocorre, então, a disponibilidade de água para que haja o suprimento da capacidade de campo (C) do solo e, ultrapassada esta, ocorre a Infiltração efetiva $\left(I_{e}\right)$ (Tabela 1$)$.

Figura 2 - Fluxo hídrico subterrâneo na área pesquisada

Figure 2 - Groundwater flow

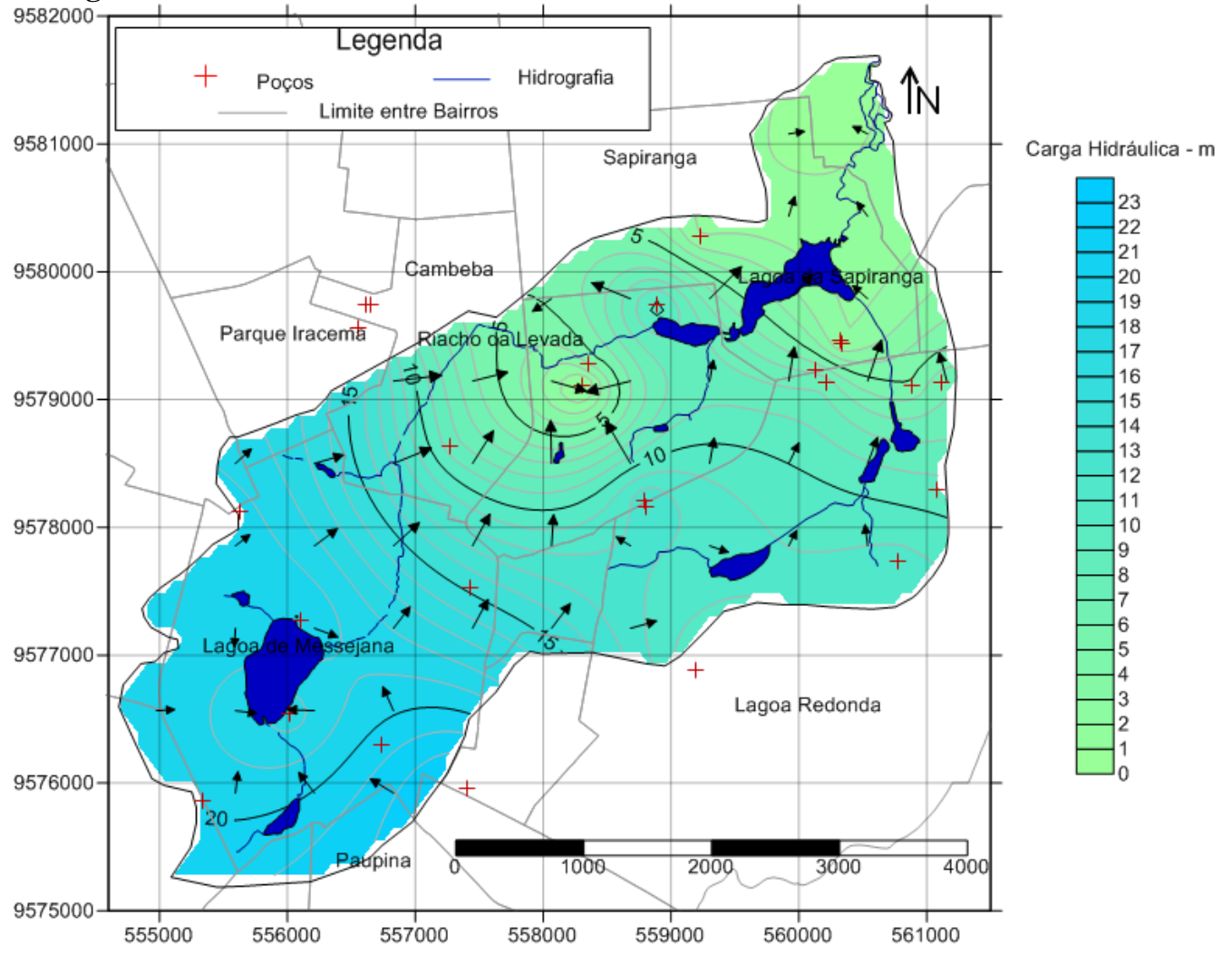

Tabela 2 - Balanço hídrico climático e infiltração efetiva na área de pesquisa

Table 2 - Climatic water balance and effective infiltration

\begin{tabular}{|c|c|c|c|c|c|c|c|c|c|}
\hline & $\mathrm{P}(\mathrm{mm})$ & $\mathrm{T}^{\circ} \mathrm{C}$ & I & $\mathrm{K}$ & ETP $(\mathrm{mm})$ & P-ETP & $\begin{array}{c}\mathrm{C} \\
(\mathrm{mm})\end{array}$ & $\begin{array}{c}\text { ETR } \\
(\mathrm{mm})\end{array}$ & $\begin{array}{c}\text { Ie } \\
(\mathrm{mm})\end{array}$ \\
\hline Jan & 131,81 & 27,33 & 12,78 & 1,06 & 158,12 & $-26,31$ & 0 & 131,81 & 0 \\
\hline Fev & 195,01 & 27,10 & 12,62 & 0,95 & 137,34 & 57,67 & 57,67 & 137,34 & 0 \\
\hline Mar & 327,46 & 26,74 & 12,37 & 1,05 & 144,44 & 183,02 & 100 & 144,44 & 125,35 \\
\hline Abr & 348,73 & 26,69 & 12,33 & 1 & 136,63 & 212,09 & 100 & 136,63 & 212,09 \\
\hline Mai & 230,94 & 26,62 & 12,28 & 1,02 & 137,91 & 93,03 & 100 & 137,91 & 93,03 \\
\hline Jun & 160,97 & 26,25 & 12,03 & 0,99 & 127,11 & 33,86 & 100 & 127,11 & 33,86 \\
\hline Jul & 89,43 & 26,08 & 11,91 & 1,02 & 127,90 & $-38,46$ & 62,54 & 89,43 & 0 \\
\hline Ago & 30,22 & 26,42 & 12,14 & 1,03 & 135,43 & $-105,21$ & 0 & 30,22 & 0 \\
\hline Set & 20,69 & 26,83 & 12,43 & 1 & 139,24 & $-118,55$ & 0 & 20,69 & 0 \\
\hline Out & 12,07 & 27,27 & 12,74 & 1,05 & 155,25 & $-143,18$ & 0 & 12,07 & 0 \\
\hline Nov & 11,41 & 27,47 & 12,88 & 1,03 & 156,55 & $-145,14$ & 0 & 11,41 & 0 \\
\hline Dez & 33,88 & 27,63 & 12,99 & 1,06 & 164,51 & $-130,63$ & 0 & 33,88 & 0 \\
\hline Total & 1592,61 & - & 149,50 & - & 1720,42 & - & - & 1012,94 & 464,33 \\
\hline
\end{tabular}

Fonte de dados: Estação Agrometerológica do Campus Universitário do Pici (UFC)/Série Histórica 1966 a 2014. LEGENDA: P - precipitação; T - Temperatura; I - índice térmico; K - fator conforme latitude (VILELA; MATOS, 1975); ETP - evapotranpiração potencial; C - capacidade de campo; ETP - evapotranspiração real; Ie - infiltração efetiva 
Ressaltam-se os elevados valores de "ETP", maiores que os de "P" em 7 meses do ano, resultando em déficit hídrico climático anual de 127,8 mm. A disponibilidade de água para infiltração ocorre entre os meses de fevereiro e junho, quando a P > ETP, e a $\mathrm{ETR}=\mathrm{P}$ por haver água disponível para tal (Figura 3). No entanto, a $\mathrm{I}_{\mathrm{e}}$ ocorre nos meses de março até abril quando $C=100$ é atingido e resulta em uma RPN de 464,3 mm.

Figura 3 - Balanço hídrico climático para a área pesquisada

Figure 3 - Climatic water balance

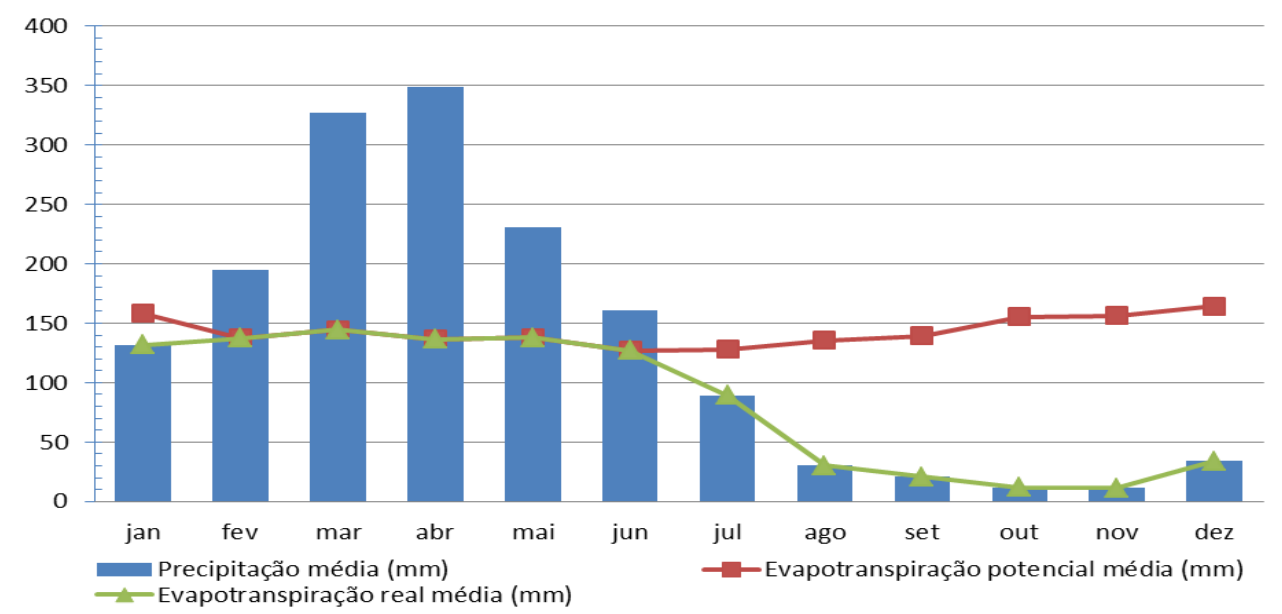

Tem-se, portanto, que ao considerar a área de 209,46 x $10^{5} \mathrm{~m}^{2}$, a RPN é estimada em $9,725 \times 10^{6} \mathrm{~m}^{3} / \mathrm{ano}$. Esse volume pode, ou não, ser efetivamente incorporado à reserva subterrânea, pois trata-se de recarga potencial. No entanto, Albuquerque et al. (2015) coloca que a estimativa de recarga pelo método do balanço hídrico pode chegar a uma correlação de 0,9 com a recarga efetiva medida através do método de monitoramento do nível estático.

A RHAlP é constituída de efluentes domésticos e vazamentos na rede de abastecimento. A contribuição dos efluentes domésticos pode ser mensurada por meio do balanço entre a água servida e o efluente disposto via rede coletora geral, ou pluvial. Quando não constatada o serviço de rede coletora de esgoto, esse passa a ser disposto em sistemas estáticos de esgotamento sanitário, pelos quais os efluentes são colocados no subsolo, e a parte liquida pode ser sucessivamente incorporada aos mananciais subterrâneos.

$\mathrm{Na}$ área de estudo foi observado que a maior parte da população não é assistida pela rede coletora de esgotamento sanitário. Portanto, cerca de 74.000 pessoas (85\%) utilizam dispositivos alternativos a esta, ou seja, SEES's, enquanto $94 \%$ da população possui sistema de abastecimento hídrico via rede geral, de acordo com o IBGE (2011).

$\mathrm{O}$ volume de água vindo de vazamentos no abastecimento de água é 1,51 milhões de $\mathrm{m}^{3} / \mathrm{ano}$, contribuindo com $59,5 \%$ da RHAIP anual (Figura 4), enquanto a quantidade diária de efluentes incorporados ao sistema subterrâneo é $2,94 \times 10^{3} \mathrm{~m}^{3}$, que anualmente corresponde ao volume de 1,07 milhões de $\mathrm{m}^{3}$. A RHAIP possui um volume total de 2,58 milhões de $\mathrm{m}^{3} / \mathrm{ano}$ e este seria capaz de abastecer anualmente 13,2\% da população da área de estudo. 
Figura 4 - Fontes de Recarga Artificial Involuntária Potencial na área pesquisada Figure 4-Source of the Involuntary Artificial Recharge

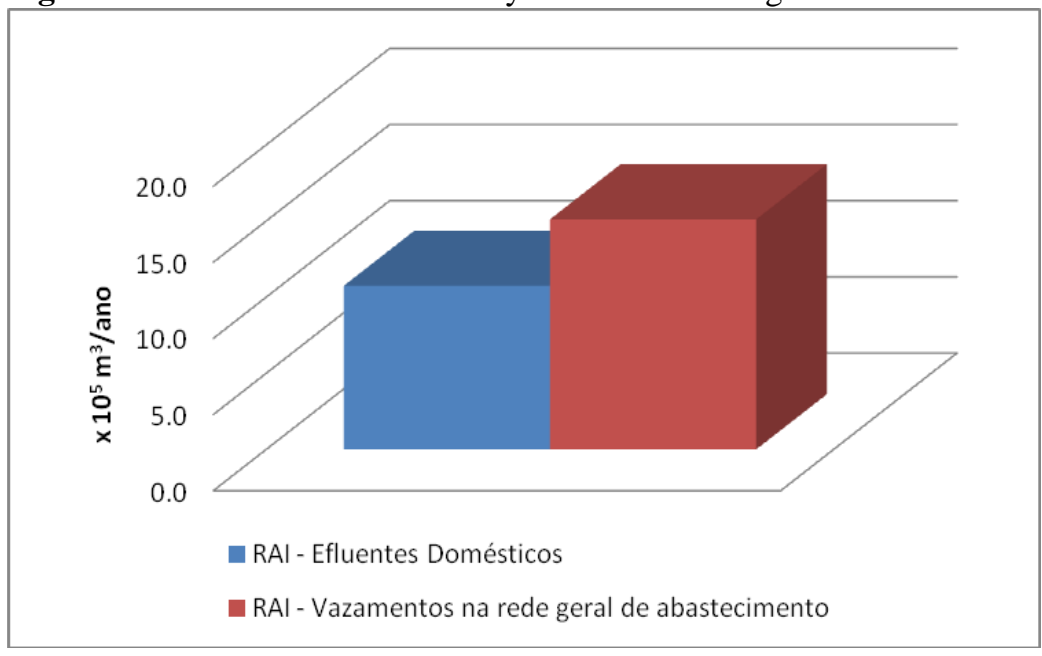

A RHNP, como esperado, contribui em maior parte para a recarga potencial do aquífero. A soma dos dois tipos de recarga é de 12,03 milhões de $\mathrm{m}^{3} / \mathrm{ano}$, e a RHAIP fornece 21\% desta (Figura 5). Considerando que Morais (2014) afirma que em Fortaleza as perdas hídricas do sistema de abastecimento são de 74,2 milhões de $\mathrm{m}^{3}$ /ano, de acordo com dados de relatórios da Companhia de Água e Esgoto do Ceará CAGECE em 2007, entende-se que tais valores foram superestimados de acordo com os dados aqui trabalhados.

Figura 5 - Volumes de Recarga Hídrica Potencial na área de pesquisa

Figure 5 - Quantity of the potential hydric recharge

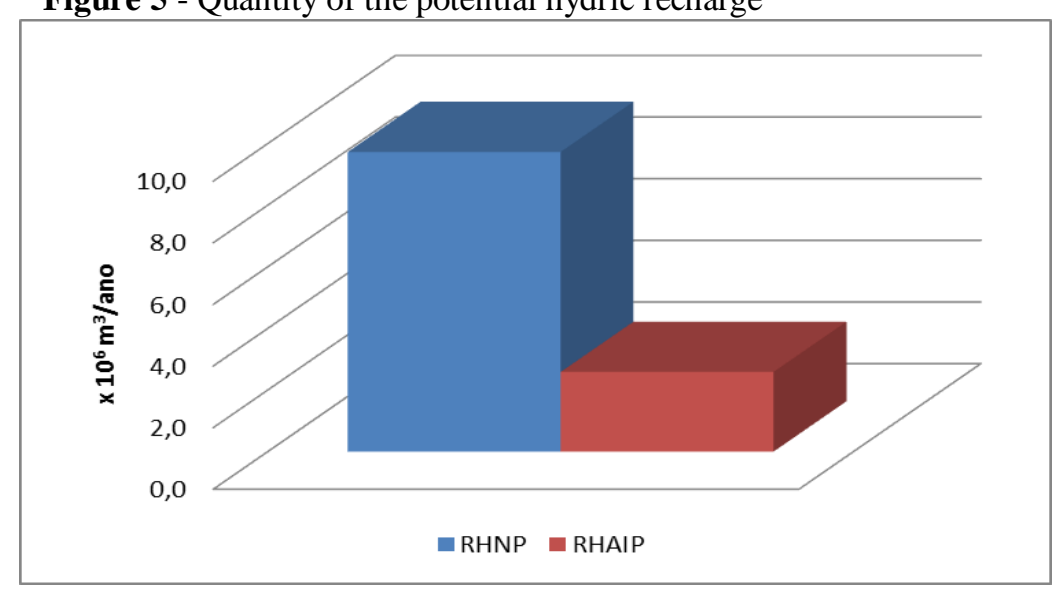

O considerável percentual de contribuição dos efluentes deve-se ao fato de que $93,8 \%$ da população são servidas do abastecimento de água via rede geral, enquanto apenas $15 \%$ possuem serviço de esgotamento sanitário. Nesse caso, é pequeno o percentual de retorno da água consumida para o serviço de tratamento do efluente, visto que não há rede coletora na grande maioria dos domicílios, situação essa característica das áreas periféricas de grandes cidades (KURIAN, 2010).
A dinâmica da recarga da água subterrânea nas cidades possui uma tendência de substituição de recarga natural para recarga artificial. Viviane-Lima (2007), em investigação na Bacia Hidrográfica de Alto Curso do Rio Tietê na Região Metropolitana de São Paulo, constatou que apesar de maior impermeabilização do solo em área não urbanizada, mais da metade da recarga desta é proveniente de vazamentos da rede de esgoto e abastecimento. Melo et al. (2014) calculam na Bacia do Rio Pirangi um volume 
de recarga efetiva utilizando um índice de perda de 0,4 para as águas provenientes dos vazamentos dos sistemas de abastecimento doméstico e rede coletora de efluentes.

É importante ressaltar que as fontes de recarga artificiais também podem funcionar como fonte de contaminação, principalmente os SEES, quando há falta de planejamento e manejo inadequado dos efluentes nesse dispositivo. Tal quantidade de efluente pode causar inviabilidade da água para fins mais nobres (VASQUES-SUÑE, 2010). Os efluentes domésticos geralmente possuem mais de 70\% de matéria orgânica, resultando em altas concentrações de compostos nitrogenados, além da presença de contaminação microbiológica, detergentes e Compostos Orgânicos Dissolvidos (COD) (MERMILOD-BLONDIN,

2015; SAMANTARA, 2015; BARRET et al., 1999)

A água incorporada no sistema hídrico subterrâneo por meio da RHAIP se configura como um processo de reuso não intencional, visto que há importância do consumo da água subterrânea na área de estudo, onde o número de poços tubulares e manuais chega a 332 de acordo com os cadastros da SRH e SIAGAS/CPRM.

\section{CONCLUSÕES}

A importância da contribuição da RHAIP foi considerável por causa da condição de saneamento, que se constata grande quantidade de sistemas estáticos de esgotamento sanitário. Somente os efluentes domésticos contribuíram com 1,07 milhões de $\mathrm{m}^{3}$ anuais, correspondendo a $41,5 \%$ da RHAIP. Os valores de recarga por vazamentos na rede geral de abastecimento foram os que mais contribuíram para a RHAIP, considerando uma estimativa de perda relativamente baixa de $22,5 \%$ segundo a CAGECE. Tais perdas correspondem a $12,8 \%$ da recarga potencial anual.

A metodologia aqui empregada é um processo estimativo, utilizando-se dados primários e secundários, na tentativa de traçar diretrizes para a recarga hídrica subterrânea em áreas urbanas. O principal desafio foi mensurar os impactos que o tipo de urbanização possui nas recargas hídricas subterrâneas. Contudo, a ferramenta SIG foi de grande utilidade ao identificar áreas de setores censitários na área de estudo e, sobretudo, relacionar os dados primários com os secundários.

A quantificação aqui realizada se aplica apenas a áreas de ocorrência de aquíferos livres. Portanto, é necessária a identificação prévia da dinâmica de contribuição da recarga natural pluvial em meio poroso.

A quantificação da RHAIP reforça e subsidia o gerenciamento por parâmetros qualitativos e quantitativos nos aquíferos urbanos, sobretudo em áreas situadas nas periferias urbanas, onde existe pouca oferta de rede coletora de esgoto. Isso tende a influenciar no aumento do volume e concentrações de contaminantes na RHAIP, aumentando assim os riscos à contaminação das águas subterrâneas.

\section{REFERÊNCIAS}

SERVIÇO GEOLÓGICO BRASILEIRO, CPRM. Atlas dos Recursos Hídricos Subterrâneos do Ceará. Fortaleza: Programa Recenseamento de Fontes de Abastecimento por Água Subterrânea no Estado do Ceará (CPRM), 2002. Escala 1:500.000.

SERVIÇO GEOLÓGICO BRASILEIRO, CPRM. Atlas Geológico do Ceará. Fortaleza: Companhia de Pesquisa de Recursos Minerais (CPRM), 2003. Escala 1:500.000.

BARRET, M. H.; HISCOCK, K. M.; DEPLEY, S.; LERNER, D. N.; TELLAN, J. H.; FRENCH, M. J. Maker Spicies For Identifying Urban Groundwater Recharge Sources: a review and case study in Nottingham, UK. Water Resource, v. 33, n. 14, p. 3083 - 3097, 1999.

CASTANY, G. Prospeccion y exploracion de las aguas subterraneas. Barcelona: Omega, 1975. 738p.

CAVALCANTE, I.N. Fundamentos Hidrogeológicos para a Gestão Integrada de Recursos Hídricos na Região Metropolitana de 
Fortaleza, Estado do Ceará. 1998. São Paulo, São Paulo, Brasil, 1998, 153 p. Tese (Doutoramento em Hidrogeologia e Recursos Minerais). Universidade de São Paulo.

CEARÁ. Projeto de monitoramento/gestão de água subterrânea de micro-áreas estratégicas da Região Metropolitana de Fortaleza, Ceará. Cadastramento de Poços. Relatório de Atividade II. Secretaria de Recursos Hídricos, Fortaleza/CE: 2002. 33 p.

COMPANHIA DE TECNOLOGIA DE SANEAMENTO AMBIENTAL - CETESB. Técnica de abastecimento e tratamento de água. 2. ed. v. 1. São Paulo, 1978.

CHAE, G.; YUN, S.; KIM, D.; KIM, K.; JOO, Y. Time-Series analysis three Years of groundwater level data (Seoul, South Korea) to characterize urban groundwater recharge. Quarterly Journal of Engineering Geology and Hydrogeology, 43, p. $117-127,2010$.

CHOI, W.; GALASINSK, U.; CHO, S.; HWANG, C. A Spatiotemporal Analysis of Groundwater Level Changes in Relation to Urban Growth and Groundwater Recharge Potential for Waukesha County, Wisconsin. Geographical Analysis, v. 44, p. 219-234, 2012.

DEMÉTRIO, J. G. A.; PAIVA, A. L. R.; FREITAS, D. A. BATISTA, A. G. S.; CABRAL, J. J. S. P. Características Hidrogeológicas das Aluviões do Rio Beberibe na Área da Bateria de Poços no Bairro de Caixa d'Água, Olinda - PE. Águas subterrâneas, v. 27, n. 3. p. 111 - 126. 2013.

FEITOSA, F. A. C.; MANOEL FILHO, J.; FEITOSA, E. C.; DEMETRIO, J. G. A. (Org.). Hidrogeologia: conceitos e aplicações. $3^{\text {a }}$ ed. revisada e ampliada. Rio de Janeiro: CPRM e LABHID, 2008.

FETTER, C. W. Applied hydrogeology. New Jersey: Prentice Hall, 1994.

FOSTER, S. S. D.; CHILTON, O. J. Downstream of downtown: urban wastewater as groundwater recharge. Hydrogeology Journal, n. 12. p. 115120, 2004.

FOSTER, S. S. D.; MORRIS, B. L.; CHILTON, O. J.; Groundwater in Urban Developement - A review of linkage and concerns. In: Symposium: Impacts of urban Growth on Surface Water Groundwater Quality. Birmingham: AHS, n. 259. p. 3 - 12. 1999.

GOMES, M. C. R. Análise situacional qualitativa sobre as águas subterrâneas de Fortaleza, Ceará - Brasil como subsídio à gestão dos recursos hídricos. Fortaleza, Ceará, Brasil, 2013. 194 p. Tese (Doutoramento em Geologia) Universidade Federal do Ceará.

GOMES M.C.R. \& CAVALCANTE I.N. Análise geoquímica das águas subterrâneas de Fortaleza, Ceará - Brasil. São Paulo. Águas Subterrâneas, v.1, n.29, p. 42 - 59, 2015.

KURIAN, M. Institutions and Economic Development: a framework for understanding water services. In: KURIAN, M.; MACCARNEY, P. Peri-urban Water and Sanitation Services: policy, planning and method. New York: Springer, 2010, p. 1 - 26.

LERNER, D. N. Groundwater Recharge in Urban Areas., Atmospheric Environmental, v. 24B, n. 1, p. 29 - 33, 1990.

Identifying and quantifying urban recharge: a review. Hydrogeology Journal, $n$. 10, p. 143 - 152. 2002.

LERNER, D. N.; ISSAR, A. S.; SIMMERS, I. Groundwater Recharge: a guide to understanding and estimating Natural Recharge. Internat. Assoc. of Hydrogologists. Hannover: Heise, 1990.

MANUEL FILHO, J. Ocorrência das Águas Subterrâneas. In: FEITOSA, A. C. F.; MANUEL FILHO, J. Hidrogeologia: Conceitos e aplicações. $\quad 2^{\mathrm{a}}$ ed. Fortaleza: CPRM/REFO, LABHID-UFPE, 2000. p. 391.

MERMILLOD-BLONDIN, F.; SIMON, L. MAAZOUZI, C.; FOULQUIER, A.; DOLOLME, C.; MARMONIER, P. Dynamics of dissolved organic carbon (DOC) through stormwater. Water Resource, n. 81, p. 27-37, 2015.

MELO, J. G.; ALVES, R. S.; SILVA, J. G. Estimativa da Recarga das Águas Subterrâneas do Sistema Aquífero Barreiras na Bacia do rio Pirangi, RN. Águas Subterrâneas, v. 28, n 2, p. 
$68-81,2014$.

MORAIS, J. B. A. Caracteres hidrogeológicos do Aquífero Dunas para a gestão de recursos hídricos na Região Metropolitana de Fortaleza - Ceará. Fortaleza, Ceará, Brasil. 2011. 79 p. Dissertação (Mestrado em Geologia). Universidade Federal do Ceará.

MUNEVAR, A.; MARINÕ, M. A. Modeling Analysis of Ground Water Recharge Potencial on Alluvial Fans Using Limited Data. Ground Water, v. 37, n. 5. 1999. p. $649-659$.

POKROVSKY, D. S.; ROGOV, G. M.; KUZEVANOV, K. I. The impact of urbanisation on the hydrogeological conditions of Tomsk, Russia. In: Chilton J (ed) Groundwater in the urban environment - selected city profiles. AA Balkema, Rotterdam. n. 23, p. 217-223, 1999.

PREFEITURA DE FORTALEZA. Plano de Desenvolvimento Integrado da Região Metropolitana de Fortaleza (PLANDIRF). Fortaleza, 1972.

RUTLEDGE, A. T.; DANIEL, C.C. Testing an automated method to estimate ground-water recharge from streamflow records. Ground Water, v.32, p.180-189, 1994.

SAMANTARA, M. K.; PADHI, R. K.; SATPATHY, K. K.; SOWMYA, M. KUMARAN, P. Groundwater nitrate contamination and use of $\mathrm{Cl} / \mathrm{Br}$ ratio for source appointment. Environmental Monitor Assessment, n. 187, v. 50, p. 1 -13, 2015.

SISTEMA DE INFORMAÇÕES DE ÁGUAS SUBTERRÂNEAS (SIAGAS). Banco de dados de poços do Ceará. Disponível em: $<$ htt://www.siagasweb.cprm.gov.br. Acesso em: 8 nov. de 2015.
SOKOLOV, A. A; CHAPMAN, T. G. Métodos para cálculo do balanço hídrico - um Guia Internacional para Pesquisas e Práticas. Tradução Unesco, Eletrobras,1978.

THORNTHWAITE, C. W. An approach toward a rational classification of climate. Geographical Review, v. 38 n.1., p. 55-94, 1948.

UNITED NATIONS. World Urbanization Prospects: The 2005 Revision Population Database Department of Economic and Social Affairs, Population Division, United Nations, New York, 2005.

\section{VASCONCELOS, M. S. Recarga do Aquífero} Dunas/Paleodunas, Fortaleza - CE. 1999. 100 f. Tese (Doutorado em Hidrogeologia e Recursos Minerais), Universidade de São Paulo.

VAZQUEZ-SUNE, E.; CARRERA, J.; TUBAU, I.; SANCHEZ-VILA, X.; SOLER, A. An approach to identify urban groundwater recharge. Hydrology and Earth Systems Science, v. 14, p. 2085-2097, 2010.

VIVIANE-LIMA, J. B. Estimativa de recarga em áreas urbanizadas: Estudo de Caso na Bacia do Alto Tietê - SP. 2007. 220 p. Tese (Doutoramento em Hidrogeologia e Recursos Minerais) Universidade de São Paulo.

VILLELA, S.M.; MATOS, A. Hidrologia aplicada. McGraw-Hill do Brasil, São Paulo, p. 169.

VON SPERLING, M. Introdução a qualidade das aguas e ao tratamento de esgotos. 2. ed. Belo Horizonte: UFMG. Departamento de Engenharia Sanitária e Ambiental, 2009. 